\title{
Residual Stress Analysis Near a Cold Expanded Hole in a Textured Alclad Sheet Using X-ray Diffraction
}

\author{
by J.C.P. Pina, A.M. Dias, P.F.P. de Matos, P.M.G.P. Moreira and \\ P.M.S.T. de Castro
}

\begin{abstract}
In this paper we present the methods of determination and the stress obtained at the periphery of a cold expanded hole in a 2024-T3 Alclad aluminum alloy sheet. The measurements in the aluminum clad were performed by the $\sin ^{2} \psi$ method, taking experimental precautions to deal with the texture effects. In the core aluminum a special method had to be implemented to determine the stress values in a direction not accessible to the X-ray diffraction. The strains were measured in sample orientations selected according to the texture characteristics and stress factors $F_{i j}$ were used to calculate the stress tensor. The $F_{i j}$ values were determined assuming a quasi-isotropic material behavior, after concluding that the stress results were not significantly affected by factors calculated for textured material. The residual stress profile, both in the clad and in the sheet, shows a nearly axisymmetric stress state. Compressive stresses were observed near the periphery of the hole, with values that are higher on the exit than on the entrance face. Residual stresses were also higher in the hoop direction than in the radial direction. They decreased with the radial distance to the hole and affected the previous stress state over a distance of $6 \mathrm{~mm}$. The plastic deformation induced by the cold expansion is well evidenced by the FWHM values, which in the affected zone decrease with increasing distance from the hole edge.
\end{abstract}

KEY WORDS-Residual stress, crystallographic texture, $X$-ray diffraction, Alclad aluminum, cold expansion

\section{Introduction}

The cold expansion of large holes in light alloys for fatigue enhancement is an example of a process that induces beneficial residual stresses. ${ }^{1}$ Cold expansion of a hole can be achieved in a number of ways but all involve using a hard tool to plastically deform the material in both radial and hoop directions so as to permanently increase its diameter. When the tool is removed from the hole, the elastic bulk surrounding the plastically deformed material forces it to spring back so that the vicinity of the hole experiences compressive residual stresses. ${ }^{2}$ These compressive residual stresses retard the crack growth, thus increasing the fatigue life of the structure.

J.C.P.Pina (zepina@ci.uc.pt) is Auxiliary Professor, Department of Physics University of Coimbra, P-3004-516 Coimbra, Portugal. A.M. Dias is Full Professor, Department of Mechanical Engineering, University of Coimbra, P-3030-201 Coimbra, Portugal. P.F.P. de Matos and P.M.G.P. Moreira are Researchers, Institute of Mechanical Engineering (IDMEC) - FEUP, Rua Dr Roberto Frias, P-4200-465 Porto, Portugal. P.M.S.T. de Castro is Full Professor, Department of Mechanical Engineering and Industrial Management, Faculty of Engineering of the University of Porto, Rua Dr Roberto Frias, P-4200-465 Porto, Portugal.

Original manuscript submitted: May 25, 2004.

Final manuscript received: October 6, 2004.

DOI: $10.1177 / 0014485105051007$
To predict the fatigue life enhancement and improve the design, it is necessary to know the residual stress state resulting from the process. X-ray diffraction is a non-destructive and well-established technique which can be applied for the residual stress evaluation in the near surface region of crystalline solids. Its use for the study of cold expanded holes in aluminum alloys is well documented. ${ }^{2-5}$ However, these alloys can exhibit rolling and crystallization textures which, generally, make it difficult to use the technique. ${ }^{6}$ In such a situation, the possible reflection directions are restricted to small angular ranges near the intensity poles of the texture and the influences of elastic anisotropy and grain interactions on the $\mathrm{X}$-ray strain measurements may have to be taken into account.

This paper deals with the stress analysis near a cold expanded hole in an Alclad aluminum alloy sheet. Both base material and the clad exhibit rolling textures whose effects on the stress evaluation are extensively analyzed. The clad shows a texture of weak intensity and can be studied by the classical $\sin ^{2} \psi$ method, taking some precautions on the selection of the diffraction directions. In spite of its marked texture, the same method can be applied for the study of the aluminum alloy core. However, the data had to be collected in precise orientations defined according to the intensity poles of the texture. None of the orientations is coincident with the hoop direction, for which the knowledge of the residual stresses was required. The problem was solved by the stress tensor calculation.

\section{Material Information}

The sample material is the Alclad aluminum alloy 2024-T3 with a thickness of $2 \mathrm{~mm}$. It consists of an Al alloy core clad on both faces with high purity aluminum. The elastic-plastic behavior of the material was experimentally studied, and values for the yield and tensile strengths and for the Young's modulus were determined; these are given by $\sigma_{c}(0.2 \%)=310 \mathrm{MPa}$, $\sigma_{R}=440 \mathrm{MPa}$, and $E=78 \mathrm{GPa}$. The clad thickness was measured by metallographic analysis. A mean value of $41 \mu \mathrm{m}$ was measured for both faces. The sample geometry is a rectangular plate $\left(280 \times 25 \mathrm{~mm}^{2}\right)$ with a central hole of $4.83 \mathrm{~mm}$. The major axis is aligned along the rolling direction of the aluminum sheet. The cold working process was performed according to FTI specifications. ${ }^{7}$ The applied expansion was $4.5 \%$ and is given by

$$
i=\frac{(D+2 t-S H D)}{S H D} \times 100 \%
$$


where $D$ is the major mandrel diameter, $t$ is the sleeve thickness, and $S H D$ is the starting hole diameter.

\section{Experimental Procedure}

The X-ray diffraction measurements were performed on a four-circle goniometer, provided with a germanium detector. $\mathrm{Cu}-\mathrm{K} \alpha$ radiation was used for the data collection. The work was initiated by the study of the coating on both faces and was continued by the analysis of the core alloy. For this purpose, the coating was removed near the periphery of the hole by using electrolytic polishing. The hole was previously filled with an epoxy resin to avoid the wall attack. The removal was accomplished in several steps until a thickness between 35 and $40 \mu \mathrm{m}$ was achieved. This process was controlled by using a $1 \mu \mathrm{m}$ precision micrometer. Optical microscopy was also used to ensure that the core material remained intact.

\section{Texture Analysis}

The texture was studied on both faces of the plate in points close to the hole. For this purpose, the 111, 200, 220, and 311 incomplete pole figures were obtained by using twodimensional discontinuous scanning, and varying $\psi$ and $\phi$ angles in steps of $5^{\circ}$, for $\psi=0^{\circ}-65^{\circ}$ and $\phi=0^{\circ}-360^{\circ}$. The background was subtracted, and correction factors were applied for absorption and defocalization. The correction factors were calculated by analysis of the intensity reflected from an $\mathrm{Al}$ powder, under the same conditions as the specimens. The four pole figures data were processed to calculate the orientation distribution function (ODF) using an iterative seriesexpansion method (harmonic method), proposed by Dahms and Bunge, ${ }^{8}$ with expansion up to $L=22$.

\section{Residual Stresses}

The residual stresses were measured on both faces at locations distributed every $0.5 \mathrm{~mm}$ along the directions shown in Fig. 1, which correspond to the rolling $\left(\theta=90^{\circ}\right)$ and transverse $\left(\theta=0^{\circ}\right)$ directions of the sheets. By using a mask, the irradiated area was limited to $1 \times 2 \mathrm{~mm}^{2}$ in the radial and hoop directions, respectively.

The goal of this work was the determination of the stress values in the hoop and radial directions. This was easily fulfilled for the coating, in spite of the crystallographic texture, which, being weak, showed a reduced influence on the stress evaluation process. The data were acquired in two perpendicular directions and the stresses were calculated by the classical $\sin ^{2} \psi$ method, once the $d-\sin ^{2} \psi$ plots showed a linear distribution. The experimental parameters listed in Table 1 were used and the peak positions were calculated by the center of gravity method with a threshold of $30 \%$.

\section{Residual Stresses in the Aluminum Alloy Core}

The aluminum alloy is characterized by a strong crystallographic texture, whose effects were considered at two steps of the X-ray diffraction stress analysis: the data collection and the stress calculation. The data could only be collected in precise directions, distributed according to the intensity poles of the texture. The identification of such directions took into account the X-ray wavelength and the diffracting planes. $\mathrm{Cu}$ $\mathrm{K} \alpha$ radiation was selected, because for aluminum it is low absorbed and allows diffracting planes at high $2 \theta$ angles. The \{422\} planes that diffract at $137.4^{\circ}$, instead of the $\{333\}$

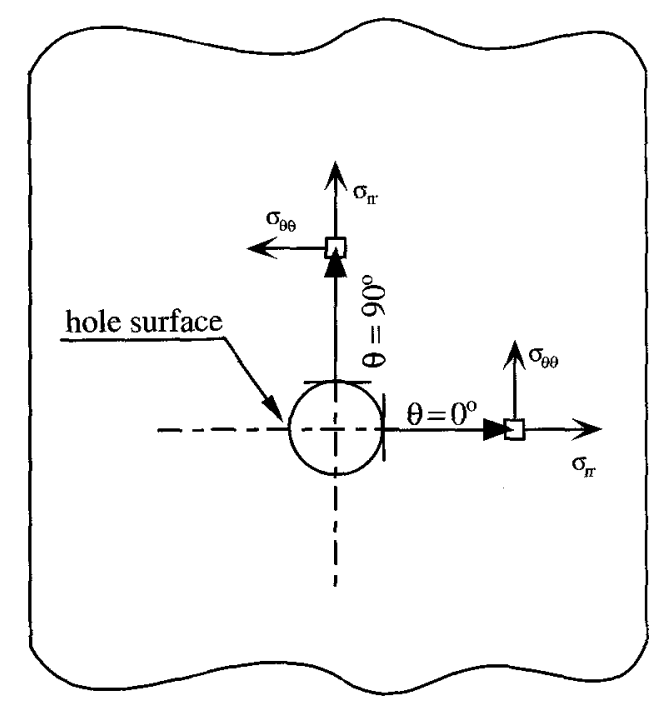

Fig. 1-Definition of the radial $\left(\sigma_{r r}\right)$ and hoop $\left(\sigma_{\theta \theta}\right)$ stresses for the rolling $\left(\theta=90^{\circ}\right)$ and transverse $\left(\theta=0^{\circ}\right)$ directions

planes diffracting at $162.5^{\circ}$, have to be selected to avoid the interference of the mask used to limit the irradiated area. Due to the principal component of the crystallographic texture, the respective reflections are only accessible for the strain measurement at inclination angles of $30^{\circ}$ and $54.7^{\circ}$. However, the experimental analysis has shown that $0^{\circ}$ and $35.3^{\circ}$ could also be used, even though with a lower diffracted intensity. These two directions are related to the isotropic distribution of the crystals and the secondary component of the texture, respectively. To improve the data statistics, directions that take into account the scatter of the crystallographic orientations were also selected. Table 2 shows all the used $\psi$ directions.

Concerning the selection of the $\varphi$ orientations, it can be observed in Fig. 1 that the rolling direction corresponds to $\sigma_{\theta \theta}$ for $\theta=0^{\circ}$ and to $\sigma_{r r}$ for $\theta=90^{\circ}$. This direction is accessible to the X-ray diffraction and can be taken as $\varphi=0$. The normal direction corresponds to the other stress components shown in Fig. 1, but it is not a good diffracting orientation. As a consequence, these components cannot be directly calculated, but the problem can be solved by the stress tensor calculation. For this purpose, at least three $\varphi$ orientations have to be selected. Their definition was based on the restrictions imposed by the software employed for the stress calculation. It is necessary to choose $\varphi=0$ with all the other $\varphi$ directions having to be distributed in equal $\Delta \varphi$ intervals. The determination of these intervals was based on the analysis of the (422) pole figure, which is relative to the planes used for the stress determination. It was calculated from the ODF results and is shown in Fig. 2. As can be observed, the intensity poles are distributed at $\Delta \varphi=60^{\circ}$ intervals, beginning at the $\varphi=0^{\circ}$ direction. This also corroborates the conclusion that for $\varphi=$ $90^{\circ}$ the data collection is not possible.

The first experiments were conducted by using all possible six $\varphi$ directions shown in Table 2, and the parameters listed in Table 3. However, a comparison of the stress values with results calculated by using four $\varphi$ directions has shown that the scatter of the results is lower than the experimental error. This conclusion was taken into account for the following measurements which were performed with the same experimental parameters (Table 3 ), but using four $\varphi$ directions only. 


\begin{tabular}{cccccc}
\hline Planes & $\begin{array}{c}\text { Bragg } \\
\text { Angle }\left(^{\circ}\right)\end{array}$ & $\begin{array}{c}\text { Angular Step } \\
\text { Width }\left({ }^{\circ}\right)\end{array}$ & $\begin{array}{c}\text { Counting Time } \\
\text { Per Step }(s)\end{array}$ & $\begin{array}{c}\text { Number of } \psi \\
\text { Angles }\left( \pm 45^{\circ}\right)\end{array}$ & $\begin{array}{c}\text { Penetration } \\
\text { Depth }(\mu \mathrm{m})\end{array}$ \\
\hline$\{511\}+\{333\}$ & 162.5 & 0.1 & 5 & 17 & 36.4
\end{tabular}

TABLE 2-ORIENTATIONS [ ${ }^{\circ}$ ] USED FOR THE DATA COLLECTION ON THE CORE ALUMINUM

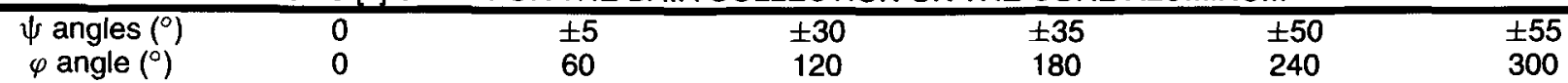

\section{TABLE 3-PARAMETERS OF THE DATA COLLECTION FOR STRESS ANALYSIS ON THE CORE ALUMINUM}

\begin{tabular}{ccccc}
\hline & $\begin{array}{c}\text { Bragg } \\
\text { Angle }\left(^{\circ}\right)\end{array}$ & $\begin{array}{c}\text { Angular Step } \\
\text { Width }\left({ }^{\circ}\right)\end{array}$ & $\begin{array}{c}\text { Counting Time } \\
\text { Per Step }(\mathrm{s})\end{array}$ & $\begin{array}{c}\text { Penetration } \\
\text { Depth }(\mu \mathrm{m})\end{array}$ \\
\hline$\{422\}$ & 137.4 & 0.12 & 8 & 34.4
\end{tabular}

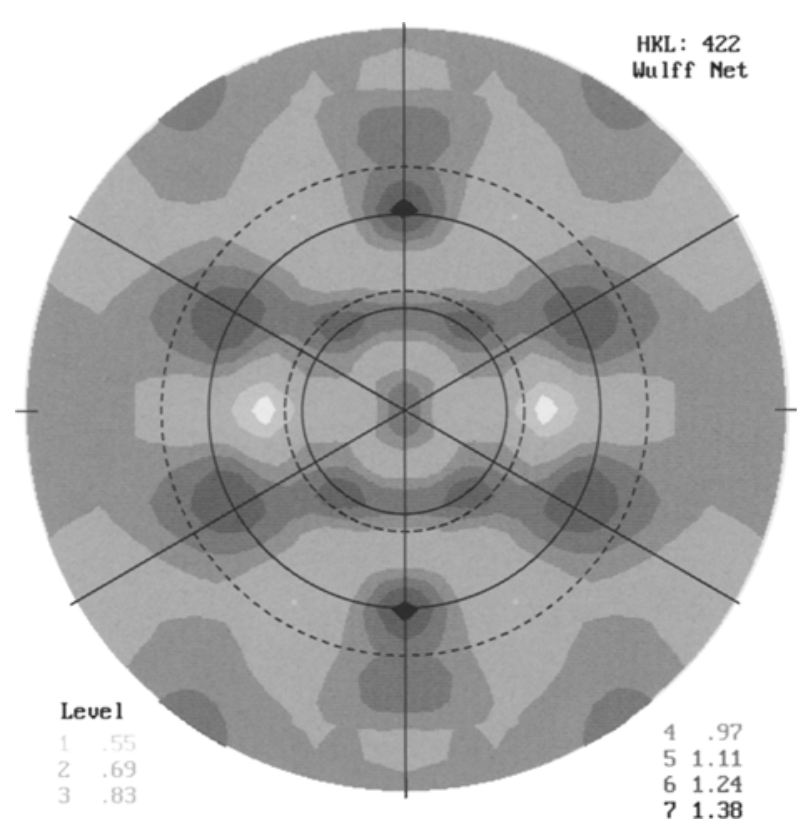

Fig. 2-(422) pole figure of the core aluminum showing the $\varphi$ and $\psi$ directions that can be used for the data collection

The texture effects on the stress calculation were analyzed by the method that Hauk ${ }^{6}$ called " $\sigma$-modelling", where the $\mathrm{X}$-ray strains are related to macro-stresses by

$$
\begin{aligned}
& \varepsilon_{\varphi \psi}(h k l)=F_{i j}(h k l, s(\Omega), S, O D F(\Omega), \varphi, \psi) . \sigma_{i j}^{l} \\
& \quad(i, j=1-3)
\end{aligned}
$$

where $F_{i j}$ are the so-called stress factors and depend on the $(\varphi, \psi)$ direction, $\Omega$ can be, for example, the three Euler angles between the crystal coordinate system and the sample coordinate system, $s(\Omega)$ are the single crystal compliances in the sample coordinate system, $S$ is the macroscopic anisotropic compliance tensor of the material, $O D F$ is the orientation distribution function of the diffracting domains, and the superscript $I$ stands for first-order stresses.
The $\varepsilon_{\varphi \psi}$ strains were calculated from the positions of the diffraction peaks and using $\mathrm{Al}$ powder as the standard material. The $F_{i j}$ components were determined by the method suggested by Sprauel et al., ${ }^{9}$ which uses the ODF and the Kröner-Eshelby model of coupling. The $\sigma_{i j}^{l}$ components were calculated by applying a least-squares method to the strains measured in six directions. This was a complex and time-consuming process, because of the data transfer between different software programs. For this reason, the results were compared with those calculated by the conventional method, which neglects the presence of texture. It was found that the results scattering was negligible, and thus the stress determination was pursued by using the latter method.

\section{Results and Analysis}

\section{Texture Results}

In all the studied points, distributed in both faces of the plate, the crystallographic texture showed the same components, without significant variations of intensity. Figures 3 and 4 show examples of the ODFs calculated in the $\mathrm{Al}-$ clad and in the aluminum alloy core, respectively. According to the ratios of the counting intensity, the texture in the Al clad is not well defined, but in the core aluminum the preferred orientation of the grains is well marked. The cube texture $\{100\}<001>$ was identified in the clad. In the core aluminum, two components could be identified: the Goss texture $\{110\}<001>$, which is dominant, and the cube texture $\{100\}<001>$, of more reduced intensity. According to the literature, the first component is due to the rolling process and the second is developed during the recrystallization treatment after rolling. ${ }^{10}$

\section{Residual Stresses}

The residual stresses in the Alclad were studied at positions distributed along the rolling direction $\left(\theta=90^{\circ} ;\right.$ Fig. 1$)$. In the aluminum sheet, the normal direction $\left(\theta=0^{\circ}\right)$ was also considered. The results are presented in Figs. 5-7, where a polynomial fitting of the values is suggested. They are plotted as a function of the distance from the hole edge to the center of the sampling volume. Comparing the stresses for the clad and the core aluminum, at first sight, they seem to 

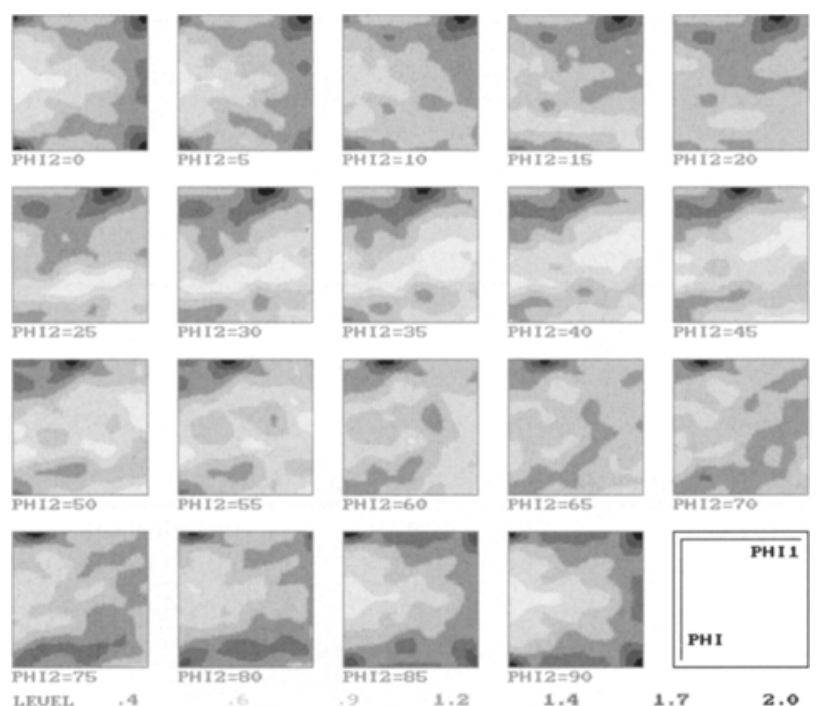

Fig. 3-Example of ODF determined in the aluminum clad
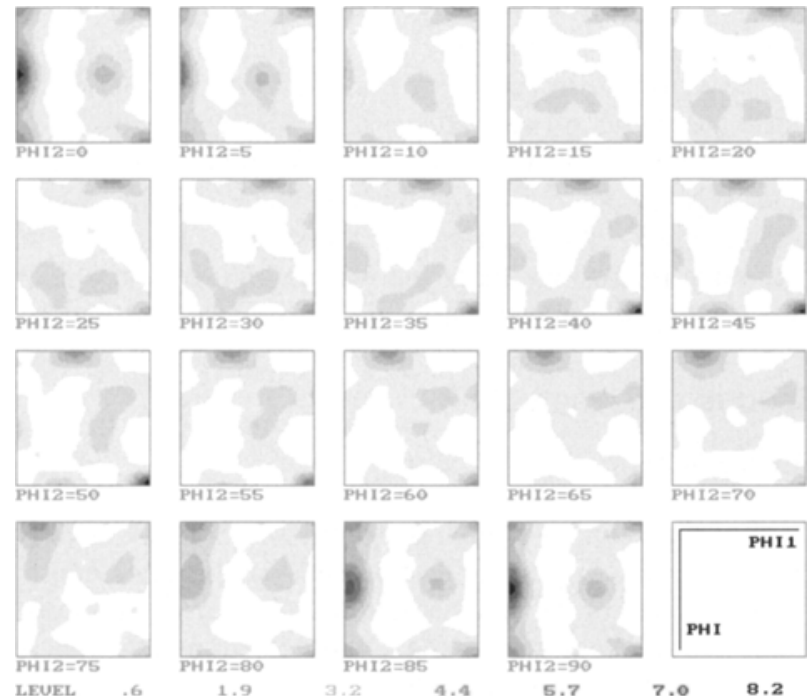

Fig. 4-Example of ODF determined in the aluminum alloy core

have different magnitudes and profiles. However, after a more accurate observation they present similarities. All the results have shown characteristics of a biaxial stress state, with shear stresses of values close to zero and the principal stresses lying in the radial and hoop directions. The stress values, both in the clad and in the aluminum sheet, are compressive in the vicinity of the hole presenting a bigger magnitude for the hoop than for the radial direction. They are also higher for the exit face than for the entrance face. At a radial distance of about $5 \mathrm{~mm}$ from the hole edge, the residual stresses seem to be stabilized. However they have different behavior: in the clad they remain compressive, whereas in the core material they tend to be completely released.

The stabilization of the residual stresses over distances of the order of $5 \mathrm{~mm}$ from the hole edge is corroborated

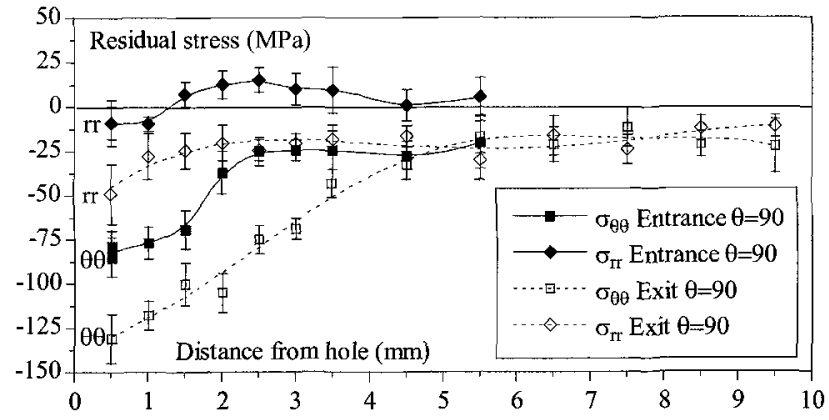

Fig. 5-Residual stresses on both faces of the Alclad

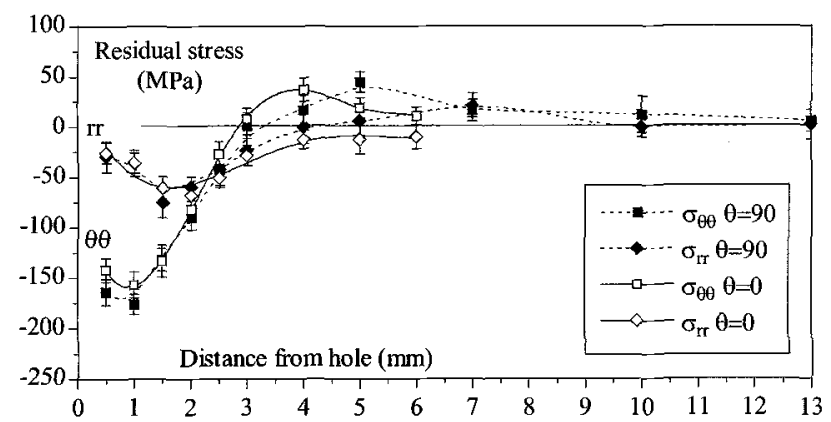

Fig. 6-Residual stresses determined on the entrance face of the aluminum sheet for $\theta=90^{\circ}$ and $\theta=0^{\circ}$

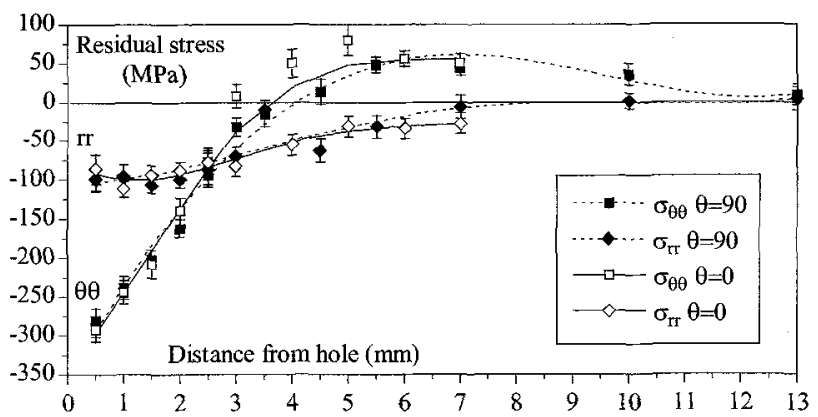

Fig. 7-Residual stresses determined on the exit face of the aluminum sheet for $\theta=90^{\circ}$ and $\theta=0^{\circ}$

by the peak breadth values at half-maximum intensity. As shown in Figs. 8 and 9, for the clad and for the core material, respectively, the values, although constant inside the error bars, decrease in the work-hardened region, and later they show a tendency to stabilize. In Fig. 8 a small difference can be observed between the values for the exit and the entrance faces of the Alclad. In Fig 9, for the aluminum sheet, this difference is only detected in the $\theta=0$ direction. Because the peak widths at half-maximum (FWHM) can be related with the degree of plastic deformation; these results show the extent of the affected zone and denote a higher plastification in the exit face, in spite of the higher stress values.

The compressive stresses of the Alclad were confirmed by measurements in points distant enough from the hole, where the cold working effect is not observed. Values of the order 


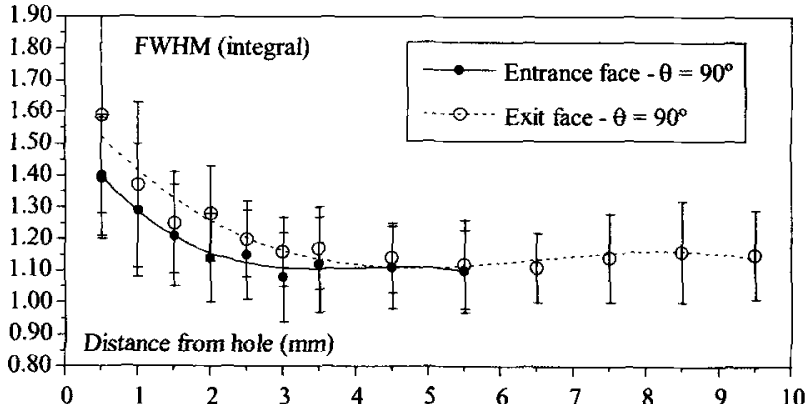

Fig. 8-Mean FWHM values on both faces of the Alclad

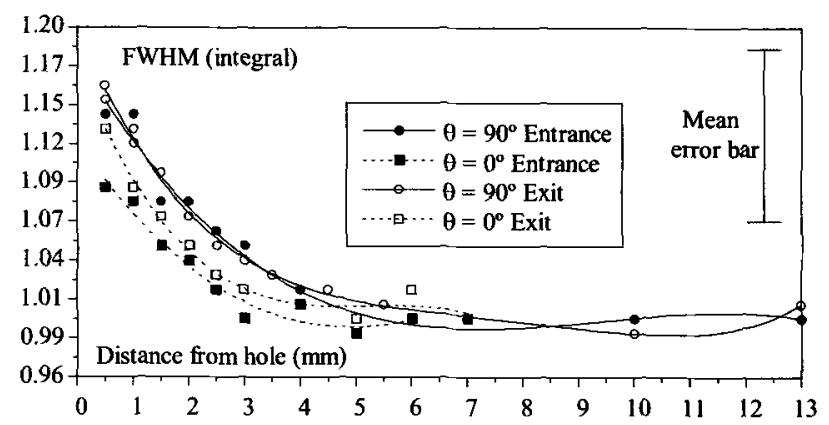

Fig. 9-Mean FWHM values on both faces and directions of the aluminum sheet

of $-25 \mathrm{MPa}$ were found for both faces, using the standard method of measurement. However, using the same X-ray wavelength and a low angle incidence method, as described in Marques et al., ${ }^{11}$ stresses of $-40 \pm 8(\mathrm{MPa})$ and $-55 \pm 15(\mathrm{MPa})$ were determined at incidence angles of $10^{\circ}$ and $5^{\circ}$, respectively. The $\mathrm{Cu}-\mathrm{K} \alpha$ radiation at these angles has a mean depth penetration of the order of $17 \mu \mathrm{m}(\approx$ half normal incidence), and thus the higher values may be due to a stress gradient in the Alclad.

The higher compressive stresses on the exit face, compared to those of the entrance, also suggest a through-thickness variation of the stress field. Similar differences have been determined by others. ${ }^{4}$ This effect can be explained by a throughthickness non-uniform deformation, owing to different mechanical constraints at different segments of thickness, while the hard tool is pulled across the aluminum sheet.

The stresses determined on the core aluminum by $\mathrm{X}$-ray diffraction were compared with results calculated by the finite-element method (FEM). ${ }^{12}$ The application of this method has, in turn, considered two models of the mechanical behavior of the material: an elastic perfectly plastic (MEPP) and an hardening behavior. As an example, Figs. 10 and 11 show the comparison of the radial and the hoop stresses, respectively, for the $\theta=90^{\circ}$ direction. For distant points from the hole, there is good agreement between both results if an elastic perfectly plastic model is used. However, it becomes not as good when the hardening behavior model is used. For distances close to the hole, the FEM results do not agree well with the experimental values. This discrepancy is linked to the difficulty to resolve the steep stress gradients by $\mathrm{X}$-ray diffraction. As a consequence, the peak values predicted by

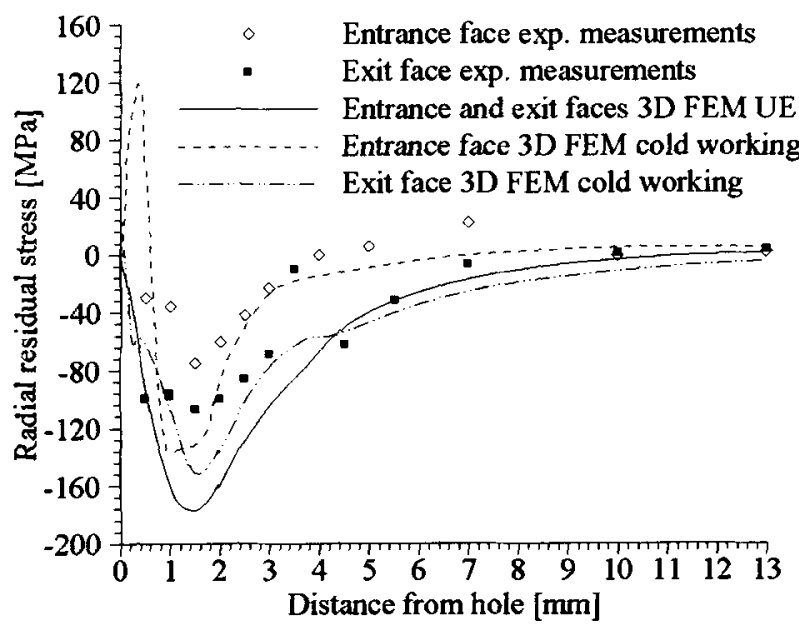

Fig. 10-Comparison of the X-ray (experimental) and FEM results for the radial stresses $\left(\sigma_{r r}\right)$ in the $\theta=90^{\circ}$ direction

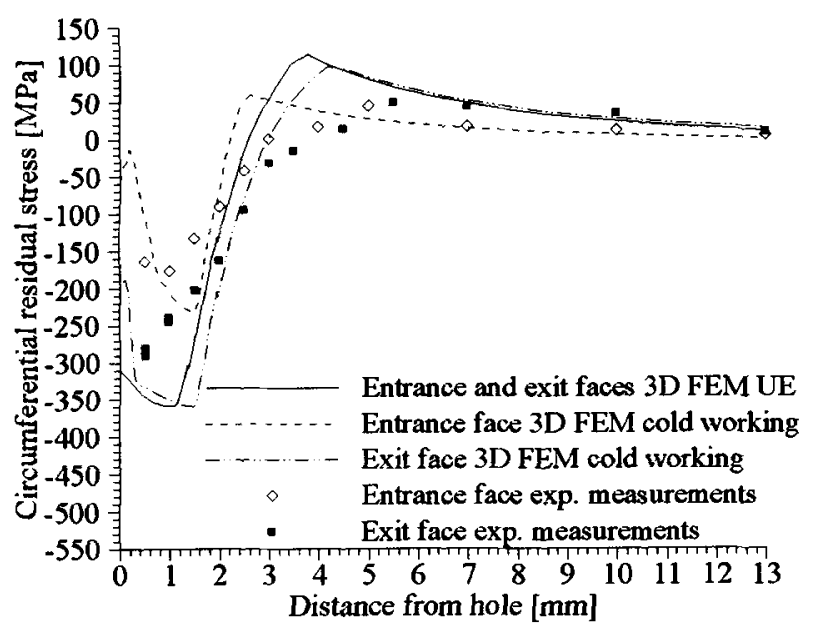

Fig. 11-Comparison of the $X$-ray (experimental) and FEM results for the hoop stresses $\left(\sigma_{r r}\right)$ in the $\theta=90^{\circ}$ direction

finite-element simulation became underestimated, as already reported by others. ${ }^{13,14}$

\section{Conclusions}

The X-ray diffraction method was applied for the residual stress evaluation on a textured aluminum sheet. The possible reflection orientations were constrained to small angular ranges near the intensity poles of the texture, but, by performing the stress tensor calculation, the stresses were determined for a sample direction where the diffracted intensity was quite null. Linear lattice-strain distributions were always observed and the stress state was calculated using stress factors of quasi-isotropic material.

The residual stresses were determined in the Alclad and in the aluminum alloy sheet. The alloy showed larger stress values, because it is much stronger than the cladding. The residual stress state, both in the clad and in the aluminum sheet, has the principal stress directions coincident with the 
radial and hoop directions. The stress values are compressive in the vicinity of the hole, presenting a bigger magnitude for the hoop than for the radial direction. They are also higher for the exit face than for the entrance.

The cold expansion induces a plastic deformation in the vicinity of the hole, which extends to a radial distance of about $5 \mathrm{~mm}$ from the hole edge.

The comparison of the X-ray diffraction results with those calculated from FEMs shows good agreement if an elastic perfectly plastic model is assumed. The agreement is not observed for distances close to the hole, where it is difficult to resolve the steep stress gradients by X-ray diffraction. As a consequence, the values predicted by finite-element simulation became underestimated.

\section{Acknowledgments}

This work is part of the IDMEC contribution for the ADMIRE project (contract G4RD-CT-2000-0396) of the European Union. The X-ray measurements were performed in the frame of the POCTI/33681/CTM 2000 Project, which was approved by the National Foundation for the Science and Technology (FCT) and the POCTI programme, and sponsored by the European Found FEDER.

\section{References}

1. O'Brien, E., "Residual Stress - 'Friend' and 'Foe'. A Civil Aircraft Perspective," Proceedings of the 6th International Conference on Residual Stresses (ICRS6), Oxford, UK, 10-12 July, Vol. 1, IOM Communications, $13-21(2000)$.

2. Ozdemir, A.T., Wang, D.Q., and Edwards, L., "Measurement of the $3 D$ Residual Stress Distribution at Split Sleeve Cold Expanded Holes," Proceedings of the 4th International Conference on Residual Stresses (ICRS4), Baltimore, MD, 8-10June, Society for Experimental Mechanics, 1144-1153 (1994).

3. Priest, M., Poussard, C.G., Pavier, M.J., and Smith, D.J., "An Assessment of Measured and Predicted Residual Stresses Around Cold Worked
Holes in Al 2024," Proceedings of the 4th International Conference on Residual Stresses (ICRS4), Baltimore, MD, 8-10 June, Society for Experimental Mechanics, 324-332 (1994).

4. Stefanescu, D., Edwards, L., and Fitzpatrick, M.E., "X-ray Diffraction Measurement of the Residual Stresses Surrounding a Cold Expanded Hole," Materials Science Forum, 404-407, 185-190 (2002).

5. Stefanescu, D., Dutta, M., Wang, D.Q., Edwards, L., and Fitzpatrick, M.E., "The Effect of High Compressive Loading on Residual Stresses and Fatigue Crack Growth at Cold Expanded Holes," Journal of Strain Analysis and Engineering Design, 38(5), 419-427 (2003).

6. Hauk, V., editor, Structural and Residual Stress Analysis by Nondestructive Methods, Elsevier Science, Amsterdam (1997).

7. FTI, "Cold Expansion Holes Using the Standard Split Sleeve System and Countersink Cold Expansion," Fatigue Technology Inc., 150 Andover Park West, Seattle, WA (2002).

8. Dahms, M. and Bunge, H.J., "The Iterative Series-expansion Method for Quantitative Texture Analysis. I - General Outline," Joumal of Applied Crystallography, 22, 439-447 (1989).

9. Sprauel, J.M., François, M., and Barral, M., "Calculation of $X$-ray Elastic Constants on Textured Materials Using Kröner Model," Proceed ings of the 2nd International Conference on Residual Stresses (ICRS2), Nancy, France, 23-25 November, Elsevier Applied Science, London, 172$177(1988)$.

10. Kocks, U.F, Tomé, C.N., and Wenk, H.R., editors, Texture and Anisotropy. Preferred Orientations in Polycrystals and Their Effect on Materials Properties, Cambridge University Press, Cambridge (1998).

11. Marques, M.J., Dias, A.M., Gergaud, P., and Lebrun, J.L., "A Methodology Development for the Study of Near Surface Gradients," Materials Science Engineering A, 287, 78-86 (2000).

12. Matos, P., Moreira, P., Pina, J., Dias, A.M., and de Castro, P.M.S.T "Residual Stresses Around an Expanded Hole in an Aluminum Clad Sheet," Proceedings of the 7th International Conference on Residual Stress (ICRS7), Xi'an, China, 14-16 June 2004, in the Proceedings of ICRS7, CD ROM (2004).

13. Cook, R. and Holdway, P., "Residual Stresses Induced by Hole Cold Expansion," Computer Methods and Experimental Measurements for Sur face Treatment Effects, C.A. Brebbia and M.H. Aliabadi, editors, Wessex Institute of Technology, UK, 91-101 (1993).

14. Garcia-Granada, A.A., Lacarac, V.D., Holdway, P., Smith, D.J., and Pavier, M.J., "Creep Relaxation of Residual Stresses Around Cold Expanded Holes," Journal of Engineering Materials Technology, 123, 125-131 (200l). 